\title{
Spontaneous Recovery from Extinction Depends on the Reconsolidation of the Acquisition Memory in an Appetitive Learning Paradigm in the Honeybee (Apis mellifera)
}

\author{
Nicola Stollhoff, Randolf Menzel, and Dorothea Eisenhardt \\ Freie Universität Berlin, Fachbereich Biologie/Chemie/Pharmazie, Institut für Biologie, Neurobiologie, 14195 Berlin, Germany
}

\begin{abstract}
Memory retrieval initiates two consolidation processes: consolidation of an extinction memory and reconsolidation of the acquisition memory. The strength of the consolidation processes depends on both the strength of the acquisition memory and the strength of retrieval trials and is correlated with its sensitivity to inhibition. We demonstrate that in the honeybee (Apis mellifera), memory retrieval of a consolidated appetitive olfactory memory leads to both consolidation processes, depending on the number of retrieval trials. Spontaneous recovery from extinction is induced by many (five), but not by few (one and two), retrieval trials. Spontaneous recovery is blocked by emetine, an inhibitor of protein synthesis. We conclude that reconsolidation of the acquisition memory underlies spontaneous recovery.
\end{abstract}

Key words: extinction; honeybee; reconsolidation; retrieval; spontaneous recovery; emetine

\section{Introduction}

Retrieving a learned association by presenting the conditioned stimulus (CS) without presenting the reinforcement by the unconditioned stimulus (US) results in the reduction of the conditioned response (CR). This characteristic behavior is called "extinction" (Pavlov, 1927; Myers and Davis, 2002; Bouton, 2004). The process underlying extinction is regarded as a learning process (Bouton, 2004) resulting in an extinction memory (Vianna et al., 2001; Berman et al., 2003; Santini et al., 2004). Extinction learning does not eliminate the previously formed memory of the CS-US association, because the extinguished CR returns in a time- and context-dependent manner, as indicated by three characteristic behavioral phenomena: reinstatement, renewal, and spontaneous recovery of the CR. Accordingly, after extinction learning, two opposing memories have been formed: an acquisition memory of the CS-US association and an extinction memory of the CS-no US association (Bouton, 2004).

Retrieving a learned association does not always result in extinction. It may lead to an opposing behavioral phenomenon, stabilization of the CR. In this case, the CS-only trial transfers the acquisition memory from an inactive, stable protein synthesisindependent memory into an active and unstable protein

Received Jan. 11, 2005; revised March 24, 2005; accepted March 27, 2005.

This study was supported by the VolkswagenStiftung (I/77378) and a position for D.E. from the Deutsche Forschungsgemeinschaft (EI512/1-1). We thank Martina Kemmer, Julia Thibaut, and Melanie Karrenbrock for excellent technical assistance. We thank Dr. Walter Farina (Universidad de Buenos Aires, Buenos Aires, Argentina) for providing support and laboratory space. We thank Dr. Rodrigo De Marco for help with the statistics and Mary Wurm for help with this manuscript.

Correspondence should be addressed to Dorothea Eisenhardt, Freie Universität Berlin, Fachbereich Biologie/ Chemie/Pharmazie, Institut für Biologie, Neurobiologie, Königin-Luise-Straße 28/30, 14195 Berlin, Germany. Email: theodora@zedat.fu-berlin.de.

DOI:10.1523/JNEUROSCI.0117-05.2005

Copyright $\odot 2005$ Society for Neuroscience $\quad$ 0270-6474/05/254485-08\$15.00/0 synthesis-dependent acquisition memory. This acquisition memory then undergoes a consolidation process that results in its stabilization and hence the stabilization of the $\mathrm{CR}$, a process that is referred to as reconsolidation (Spear, 1973; Sara, 2000; Nader, 2003; Dudai and Eisenberg, 2004). Either consolidation of extinction memory or reconsolidation of the acquisition memory has been observed in different studies in vertebrates (Nader et al., 2000; Berman and Dudai, 2001; Vianna et al., 2001; Anokhin et al., 2002; Debiec et al., 2002) and in invertebrates (Yamada et al., 1992; Sekiguchi et al., 1997; Pedreira et al., 2002; Child et al., 2003; Sangha et al., 2003a,b), leading to the hypothesis that consolidation of extinction memory learning and reconsolidation of acquisition memory may be two competing processes (Nader, 2003; Dudai, 2004). Recent studies confirm this hypothesis by showing a separation between both processes by varying the strength of the CS (Eisenberg et al., 2003; Pedreira and Maldonado, 2003; Suzuki et al., 2004). When protocols were used to induce extinction, the consolidation of the extinction memory was the one affected by protein synthesis inhibitors. When protocols that did not induce significant extinction were used, the reconsolidation of the initial acquisition memory was the protein synthesis-dependent process. These results led to the hypothesis that the dominant memory trace must be the one most affected by protein synthesis (Nader, 2003; Dudai, 2004).

Most of the studies on the relationship between consolidated extinction memory and reconsolidated acquisition memory examined aversive learning paradigms. Here, we report data on appetitive learning in the honeybee (Apis mellifera). In the olfactory conditioning of the proboscis extension response (PER), honeybees learn to associate an odorant (CS) with a sucrose reward (US) (Kuwabara, 1957; Menzel et al., 1974; Bitterman et al., 1983), leading to multiple olfactory memories (Menzel, 2001). We asked what impact different numbers of CS-only trials have 
on memory formation if applied after the olfactory memory has been consolidated.

\section{Materials and Methods}

\section{General procedures related to behavior}

One day before conditioning, foraging honeybees (Apis mellifera) were caught as they left the hive, immobilized by cooling, and harnessed in small metal tubes. One hour later, bees were fed to satiation with sucrose $(1 \mathrm{M})$. Experiments were started on the following day. During the rest of the experiment, animals were fed every afternoon (between 3:00 and 6:00 P.M.) with four droplets of sucrose solution $(\sim 10 \mu \mathrm{l})$. The animals were fed at least $1 \mathrm{~h}$ after the last presentation of a CS trial. Between the test sessions, bees were kept in a dark and humid box at room temperature.

\section{Conditioning of the PER}

Acquisition. An acquisition trial consists of moving a bee from its resting position to the inlet of an exhaust fan. The odor (CS) was delivered after $10 \mathrm{~s}$ of accommodation time. Carnation oil from the pharmacy was used as CS and delivered through a $20 \mathrm{ml}$ syringe that was loaded daily with 4 $\mu \mathrm{l}$ of carnation oil. The odor was presented for $5 \mathrm{~s}$. Two seconds after the odor onset, sucrose (US) was applied by touching the antennas with a sucrose-moistened toothpick, and the bees were allowed to lick sucrose for $4 \mathrm{~s}$. Acquisition consisted of three such pairings with an intertrial interval (ITI) of $10 \mathrm{~min}$. A bee scored positive when it extended its proboscis between the onset of the CS and the presentation of the US.

CS-only trial presentation. CS-only trials were presented $24 \mathrm{~h}$ after acquisition and consisted of $5 \mathrm{~s}$ CS presentations without reinforcement of the US. If more than one CS-only trial was presented, the intertrial interval was $10 \mathrm{~min}$.

Retention. Retention trials were performed the same way as CS-only trials.

\section{Emetine treatment}

Emetine (catalog \#45160; Fluka, Buchs, Switzerland) was dissolved in PBS (in mM: $137 \mathrm{NaCl}, 2.7 \mathrm{KCl}, 10.1 \mathrm{Na}_{2} \mathrm{HPO}_{4}, 1.8 \mathrm{KH}_{2} \mathrm{PO}_{4}, \mathrm{pH} 7.2$ ). One microliter of emetine (10 mM) was injected manually into the flight muscle using a calibrated glass capillary. Animals were injected $30 \mathrm{~min}$ before acquisition or extinction. Control groups were injected the same way with $1 \mu \mathrm{l}$ of PBS.

\section{Data analysis}

Animals that survived the entire experiment, showed the PER elicited by sucrose at the end of the experiment, and did not show a spontaneous extension of the proboscis to the odor (CS) at the first CS-US pairing were included in the analysis. For the statistical analysis, differences were considered significant if the $p$ value was $<0.05$.

Test of heterogeneity between groups. The experiments consisted of three phases: acquisition, presentation of CS-only trials, and a retention test. The critical test is the retention test at the end of the experiments. To ensure that all groups within an experiment showed similar acquisition, the CRs at the last acquisition trial and at the last CS-only trial were tested for heterogeneity between groups (Zar, 1997). For all experiments, the null hypothesis was not rejected. Therefore, we concluded that the CRs of the different groups are homogenous (data not shown).

Within-group comparison. For the within-group comparison between the CR at the last CS-only trial and the CR at each retention test, we used the McNemar $\chi^{2}$ test (Zar, 1997) implemented in Statistica (StatSoft, Tulsa, OK) (see supplemental material, available at www.jneurosci.org).

Between-group comparison. The differences in CR between groups in each test were tested by the application of a G-test for contingency tables (log likelihood ratio for contingency tables).

\section{Results}

One CS-only trial applied $24 \mathrm{~h}$ after acquisition does not result in extinction

One day after acquisition, the honeybee long-term memory (LTM) is no longer susceptible to inhibitors of transcription and translation (Wüstenberg et al., 1998). It can therefore be regarded as consolidated. We asked whether one CS-only trial presented

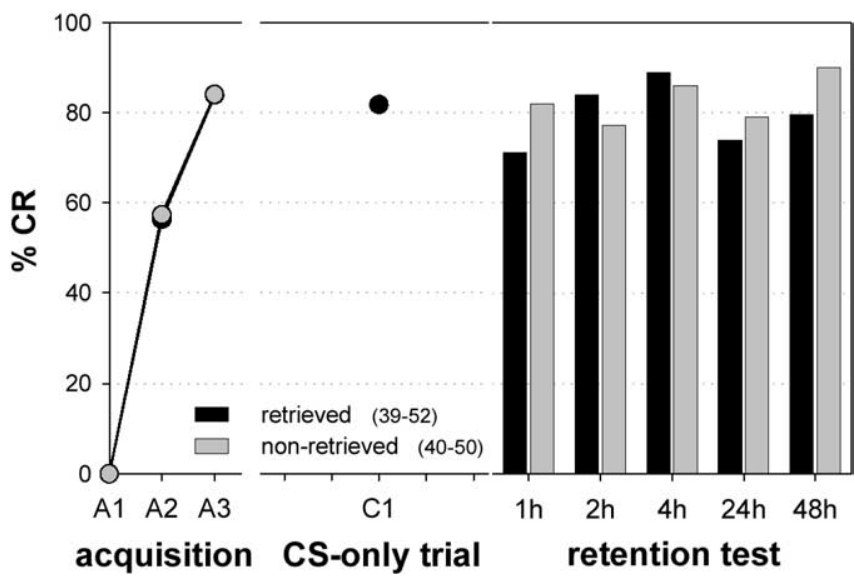

Figure 1. In an appetitive, olfactory learning paradigm, one CS-only trial presented after memory is consolidated did not lead to extinction. On day 1 , all animals were subjected to three CS-US pairings (A1-A3) with an ITI of $10 \mathrm{~min}$ (acquisition). After $24 \mathrm{~h}$, on day 2, one CS-only (C1) trial was presented. At each time point after the CS-only trial, a subgroup of animals was tested with one (S-only trial (retention test). Data from the acquisition phase and the CS-only presentations after $24 \mathrm{~h}$ were pooled for all subgroups (retrieved, nonretrieved). For detailed information on performance during acquisition and the CS-only trial of the different subgroups, see supplemental Figure 1-1 $A-E$ (available at www.jneurosci.org as supplemental material). $\% \mathrm{CR}$, Percentage of animals that show a proboscis extension response during CS presentation; black circles and bars, retrieved group; gray circles and bars, nonretrieved group. The number in parentheses represents the number of animals in the different subgroups.

after the consolidation of an olfactory memory induces extinction. We examined the time course of retention after one CS-only trial, presented $24 \mathrm{~h}$ after acquisition of an olfactory memory, and compared it with retention in a nonretrieved group (Fig. 1).

For this experiment, fixed honeybees were trained with three CS-US pairings with an ITI of $10 \mathrm{~min}$ on day 1 . On day 2 , they were divided into two groups, one of which was subjected to one CS-only trial (retrieved group). The second group acted as a control group and was not subjected to one CS-only trial but was handled in the same way (nonretrieved group). Both groups were further divided into five groups each. Each group was tested once by a retention test given at different time points $(1,2,4,24$, and $48 \mathrm{~h})$.

The retention tests of the retrieved group do not show any significant reduction in CRs compared with the nonretrieved group (Fig. 1). Also, there is no significant difference in CR between the CS-only trial and the retention test on the different time points (supplemental Fig. 1-1, available at www.jneurosci. org as supplemental material). Thus, one CS-only trial does not lead to extinction.

\section{Two CS-only trials applied $24 \mathrm{~h}$ after acquisition result in extinction}

Next, we asked whether extinction is induced after presentation of two CS-only trials. We examined the time course of retention after two CS-only trials, presented $24 \mathrm{~h}$ after acquisition of an olfactory memory, and compared it with retention in a nonextincted group (Fig. 2).

The experimental schedule was the same as for one CS-only trial, except that on day 2, two CS-only trials were presented with an ITI of $10 \mathrm{~min}$. In the retrieved group, two CS-only trials led to a reduction of conditioned responses within the CS-only session (from $85 \%$ at the first CS-only trial to $75 \%$ at the second CS-only trial) (Fig. 2). Retention tests of the retrieved group show a significant reduction in CRs compared with the nonretrieved group on each tested time point $\left(\mathrm{G}_{1 \mathrm{~h}}=8.30, p<0.01 ; \mathrm{G}_{2 \mathrm{~h}}=13.28, p<\right.$ 


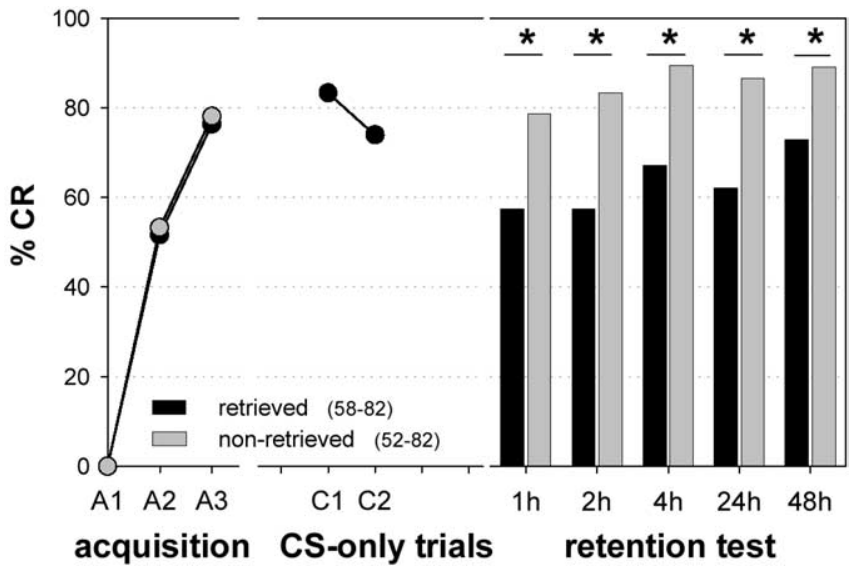

Figure 2. In an appetitive olfactory learning paradigm, two CS-only trials presented after memory is consolidated lead to extinction. On day 1, all animals were subjected to three CS-US pairings (A1-A3) with an ITI of 10 min (acquisition). After $24 \mathrm{~h}$, on day 2, two CS-only (C1, C2) trials were presented with an ITI of $10 \mathrm{~min}$. At each time point after the last CS-only trial, a subgroup of animals was tested with one CS-only trial (retention test). Data of the acquisition phase and the $\mathrm{CS}$-only presentations after $24 \mathrm{~h}$ were pooled for all subgroups (retrieved, nonretrieved). For detailed information on performance during acquisition and CS-only trials of the different subgroups, see supplemental Figure 2-1A-E (available at www.jneurosci.org as supplemental material). Asterisks indicate significant differences $(p<0.05)$ in the CRs between retrieved and nonretrieved animals of one subgroup. \% CR, Percentage of animals that show a proboscis extension response during CS presentation; black circles and bars, retrieved group; gray circles and bars, nonretrieved group. The number in parentheses represents the number of animals in the different subgroups.

$0.01 ; G_{4 \mathrm{~h}}=9.79, p<0.01 ; \mathrm{G}_{24 \mathrm{~h}}=8.82, p<0.01 ; G_{48 \mathrm{~h}}=4.51$, $p<0.05$; $\mathrm{df}=1$ ). Thus, presentation of two nonreinforced CSonly trials induces extinction.

Retention after two CS-only trials significantly declined in the 1 and $2 \mathrm{~h}$ retention tests when compared with the last extinction trial (McNemar: $\chi_{1 \mathrm{~h}}{ }^{2}=9.39, p<0.01 ; 2 \mathrm{~h}: \chi_{2 \mathrm{~h}}{ }^{2}=8.47, p<$ $0.01 ; \mathrm{df}=1$ ) (supplemental Fig. 2-1, available at www.jneurosci. org as supplemental material). Retention rises after $2 \mathrm{~h}$ but only to the level of the last extinction trial. The CRs at the different retention tests do not differ significantly $\left(G_{\text {retrieved }}=4.88\right.$, NS; $\left.G_{\text {nonretrieved }}=4.16, \mathrm{NS} ; \mathrm{df}=4\right)$. There is no significant increase of CR between the last extinction trial and the first retention test and no significant increase of CR over time in the retention period. We therefore conclude that spontaneous recovery is not induced after two-trial extinction.

\section{Five CS-only trials applied $24 \mathrm{~h}$ after acquisition led to} extinction and spontaneous recovery

Next, we determined whether there is a correlation between the strength of the extinction and the number of CS-only trials presented. The experimental procedure was the same as for two CS-only trials, except that five CS-only trials with an intertrial interval of $10 \mathrm{~min}$ were presented on day 2 instead of two CS-only trials.

Five CS-only trials led to a considerable decrease in conditioned responses within the CS-only session (from 68\% at the first CS-only trial to $14 \%$ at the last CS-only trial) (Fig. 3). Retention tests in the retrieved group show a significant reduction of $\mathrm{CR}$ compared with the nonretrieved group on each tested time point $\left(\mathrm{G}_{1 \mathrm{~h}}=25.50, p<0.01 ; \mathrm{G}_{2 \mathrm{~h}}=24.08, p<0.01 ; G_{4 \mathrm{~h}}=7.99\right.$, $\left.p<0.05 ; \mathrm{G}_{24 \mathrm{~h}}=7.68, p<0.01 ; G_{48 \mathrm{~h}}=17.73, p<0.01 ; \mathrm{df}=1\right)$ (Fig. 3). Thus, five CS-only trials induce extinction.

Testing honey bees from the retrieved group at different time points after extinction revealed a recovery of retention. A com-

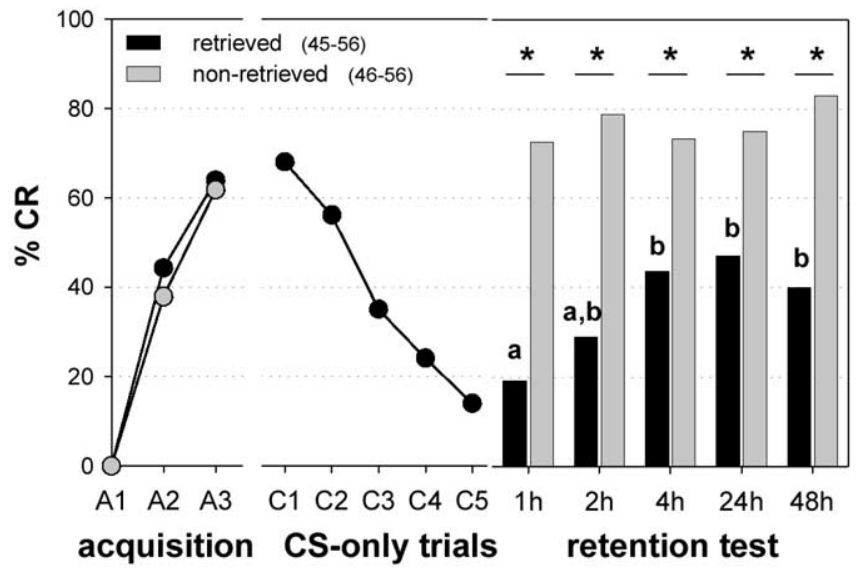

Figure 3. In an appetitive olfactory learning paradigm, five CS-only trials presented after memory is consolidated lead to extinction and spontaneous recovery. 0 n day 1 , all animals were subjected to three CS-US pairings (A1-A3) with an ITI of $10 \mathrm{~min}$ (acquisition). After $24 \mathrm{~h}$, on day 2, five CS-only trials (C1-C5) were presented with an ITI of $10 \mathrm{~min}$. At each time point after the last CS-only trial, a subgroup of animals was tested with one CS-only trial (retention test). Data from the acquisition phase and the CS-only presentations after $24 \mathrm{~h}$ were pooled for all subgroups (retrieved, nonretrieved). For detailed information on performance during acquisition and CS-only trial of the different subgroups, see supplemental Figure 3-1A-E (available at www.jneurosci.org as supplemental material). Asterisks indicate significant differences ( $p<$ 0.05 ) in the (Rs between retrieved and nonretrieved animals of one subgroup. For the retrieved groups, only bars with different letters differ significantly from one another $(p<0.05)$; nonretrieved groups do not differ from each other. \% CR, Percentage of animals that show a proboscis extension response during CS presentation; black circles and bars, retrieved group; gray circles and bars, nonretrieved group. The number in parentheses represents the number of animals in the different subgroups.

parison in each group between the last CS-only trial on day 2 and the retention test shows a significant increase of CR for all tested time points except for the $1 \mathrm{~h}$ group $\left(\chi_{1 \mathrm{~h}}{ }^{2}=0.90, \mathrm{NS} ; \chi_{2 \mathrm{~h}}{ }^{2}=\right.$ $4.90, p<0.05 ; \chi_{4 \mathrm{~h}}{ }^{2}=7.58, p<0.01 ; \chi_{24 \mathrm{~h}}{ }^{2}=9.30, p<0.01 ; \chi_{48}$ $\mathrm{h}^{2}=4.27, p<0.05 ; \mathrm{df}=1$ ) (supplemental Fig. 3-1, available at www.jneurosci.org as supplemental material). The CR of the retrieved groups rises continuously from $19 \%$ in the $1 \mathrm{~h}$ group to $48 \%$ in the $24 \mathrm{~h}$ group and decreases slightly to $40 \%$ in the $48 \mathrm{~h}$ group. The difference between the percentage of animals showing a CR in the $1 \mathrm{~h}$ group and in the 4,24 , and $48 \mathrm{~h}$ groups is significant $\left(\mathrm{G}_{1 \mathrm{~h}}\right.$ vs $G_{4 \mathrm{~h}}=6.21, p<0.05 ; \mathrm{G}_{1 \mathrm{~h}} \mathrm{vs}_{24 \mathrm{~h}}=8.84, p<0.01$; $\mathrm{G}_{1 \mathrm{~h}}$ vs $\left.G_{48 \mathrm{~h}}=4.35, p<0.05 ; \mathrm{df}=1\right)$. The CR of the nonretrieved groups did not change significantly between the tested time points $\left(G_{\text {nonretrieved }}=1.95, \mathrm{NS} ; \mathrm{df}=4\right)$. Thus, spontaneous recovery of retention (Myers and Davis, 2002; Rescorla, 2004) is induced by five CS-only trials in olfactory conditioning of bees.

Five CS-only trials induce spontaneous recovery that is inhibited by emetine

Several studies have demonstrated that consolidation of extinction memory depends on protein synthesis (Berman and Dudai, 2001; Vianna et al., 2001). If this holds true for the conditioning of the PER conditioning, the reduction in retention after five CS-only trials, as demonstrated above, should be blockable by protein-synthesis inhibitors presented during the time of extinction. We applied the protein-synthesis blocker emetine to test its effect on extinction memory and spontaneous recovery. Emetine was selected, because it inhibits consolidation of an LTM tested $1 \mathrm{~d}$ after conditioning (Fig. 4) when injected $30 \mathrm{~min}$ before three appetitive olfactory learning trials. Comparing animals treated with emetine 30 min before acquisition with control animals treated with PBS revealed a 19\% decrease of CR in the emetine- 


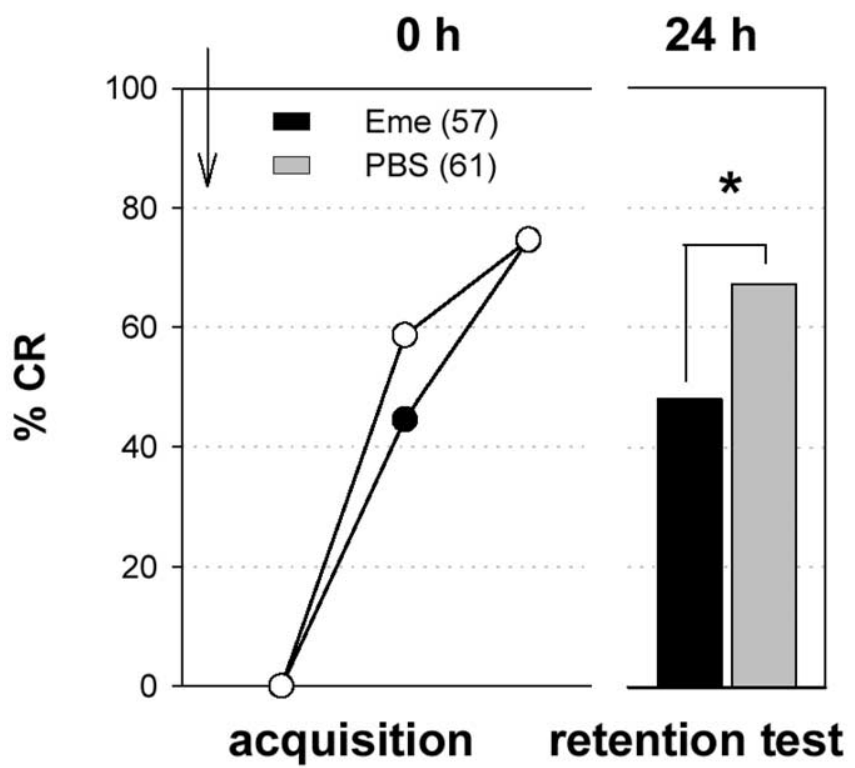

Figure 4. Emetine (Eme; $10 \mathrm{~mm}$ ) applied systemically $30 \mathrm{~min}$ before acquisition blocks longterm memory at $24 \mathrm{~h}$ after acquisition. Emetine was injected into the flight muscle $30 \mathrm{~min}$ before three CS-US pairings with an ITI of $10 \mathrm{~min}$ (acquisition). Memory was tested $24 \mathrm{~h}$ after acquisition (retention test), (emetine, $n=57 ; \mathrm{PBS}, n=61$ ). The asterisk indicates a significant difference between the CRs $(p<0.05)$. Arrow, Time of injection; gray, PBS-injected control group; black, emetine-injected group; \% CR, percentage of animals that show a proboscis extension response during $\mathrm{CS}$ presentation.

treated group. This difference between the CRs of both groups at $24 \mathrm{~h}$ is significant in the $\mathrm{G}$-test $(G=4.32 ; p<0.05$; $\mathrm{df}=1)$. We conclude that LTM is inhibited by emetine. A midterm memory, which is independent of protein synthesis, most likely accounts for the remaining CR. Here, we tested the effect of inhibition by emetine $24 \mathrm{~h}$ after the presentation of five CS-only trials. If the decrease in retention $1 \mathrm{~d}$ after extinction was a result of a newly consolidated memory, as is the $24 \mathrm{~h}$ memory after acquisition, inhibition with emetine during the five CS-only trials should lead to an increase in the CRs at a $24 \mathrm{~h}$ retrieval compared with the PBS-retrieved bees. This increase should approach the PBS nonretrieved bees' CR.

To test this hypothesis, honeybees were trained with three CS-US pairings on day 1 . On day 2, they were divided into two groups. Animals in the first group were systemically injected with emetine, and animals in the second group were injected with PBS. Each group was further divided into two groups. One of each was subjected to five CS-only trials $30 \mathrm{~min}$ after the emetine (emetine-retrieved) or PBS (PBS-retrieved) injection. The other groups acted as nonretrieved control groups (emetinenonretrieved and PBS-nonretrieved). On day three, $24 \mathrm{~h}$ after the presentation of the CS-only trials, all four groups were subjected to one CS-only test trial (Fig. 5).

On day 2, both retrieved groups (emetine-retrieved and PBSretrieved) showed a similar within-session extinction (Fig. 5A). Hence, the emetine injection had no influence on the reduction of response probabilities during the series of five CS-only trials. On day 3, the CRs of the emetine-retrieved group were significantly reduced in comparison with the PBS-retrieved group (emetine-retrieved vs PBS-retrieved: $G=4.96 ; p<0.05 ; \mathrm{df}=1$ ) (Fig. 5A). The CRs of the PBS-nonretrieved and emetinenonretrieved control groups did not differ (Fig. 5B). Hence, emetine applied $30 \mathrm{~min}$ before five CS-only trials inhibits spontaneous recovery and not extinction of the $\mathrm{CR}$, as we expected. We
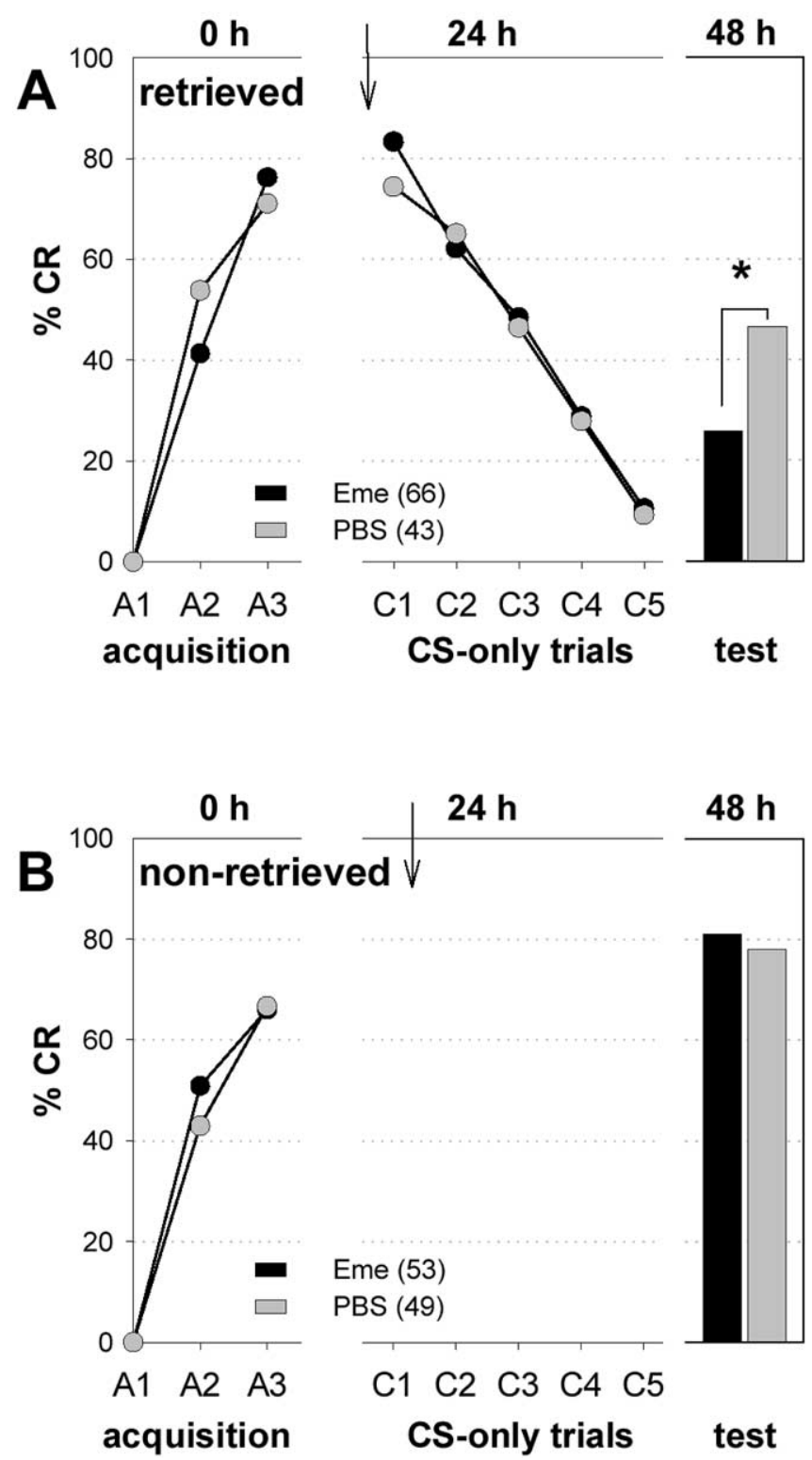

Figure 5. Emetine (Eme; $10 \mathrm{~mm}$ ) applied systemically 30 min before presentation of five CS-only trials blocks spontaneous recovery at a $24 \mathrm{~h}$ retention test. On day 1 , animals were subjected to three CS-US (A1-A3) pairings with an ITI of $10 \mathrm{~min}$ (acquisition). After $24 \mathrm{~h}$, on day 2, emetine was injected into the flight muscle 30 min before five CS-only trials (C1-C5). CS-only trials were presented with an ITI of $10 \mathrm{~min}$. 0 n day 3, memory was tested (retention test). The asterisk indicates a significant difference between the CRs $(p<0.05)$. $A$, Retrieved groups (emetine, $n=66$; PBS, $n=43$ ). $\boldsymbol{B}$, Nonretrieved groups (emetine, $n=53$; PBS, $n=49$ ). Arrow, Time of injection; gray, PBS-injected control group; black, emetine-injected group; \% $C R$, percentage of animals that showed a proboscis extension response during $C S$ presentation.

conclude from this that the consolidation of a memory trace must have been induced by five CS-only trials that counteract the extinction and that it is targeted by emetine. This meets the definition of reconsolidation of the acquisition memory, which is only visible if inhibited. The proposed memory trace is most likely the memory for the acquisition undergoing a reconsolidation process induced by five CS-only trials.

Two CS-only trials induce extinction, which is inhibited by emetine

Five CS-only trials induce spontaneous recovery, which is visible $4 \mathrm{~h}$ after extinction of a consolidated memory. As shown above, 
this spontaneous recovery is attributable to a reconsolidation of the acquisition memory.

Two CS-only trials induce extinction rather than spontaneous recovery from extinction (Fig. 2). Thus, reconsolidation of the original memory might not have been induced, and emetine treatment should result in the inhibition of the consolidation of extinction. To test this hypothesis, the same experiment was performed as described above. Only the number of CS-only trials presented on day 2 was changed from five to two CS-only trials 30 min after the injection.

The emetine injection had no influence on the reduction in response probabilities during the series of two CS-only trials on day 2, because both retrieved groups (PBS-retrieved and emetine-retrieved) showed a similar reduction of CR from the first to the second CS-only trial (from 86 and $88 \%$ to 80 and $78 \%$, respectively). On day 3 , retention of the PBS-retrieved group was significantly reduced when compared with the last extinction trial on day 2 (McNemar: $\chi^{2}=6.86 ; p<0.01$; df $=1$ ) (Fig. $6 A$ ). Retention did not change significantly in the emetine-retrieved group from days 2 to 3 (McNemar: $\chi^{2}=0, \mathrm{NS} ; \mathrm{df}=1$ ). Retention did not change in either nonretrieved control groups (Fig. $6 B$ ). The difference between the PBS-retrieved and emetine-retrieved CRs on day 3 is significant $\left(\mathrm{G}_{24 \mathrm{~h}}=4.24 ; p<0.05 ; \mathrm{df}=1\right)$. The CRs of the PBS-nonretrieved and the emetine-nonretrieved groups $\left(\mathrm{G}_{24 \mathrm{~h}}=0.06, \mathrm{NS}\right.$; $\left.\mathrm{df}=1\right)$ are not significantly different from each other on day 3 . These results demonstrate that two CS-only trials lead to the consolidation of extinction memory. If this consolidation process is blocked, retention of extinction learning is reduced and learned performance enhanced.

\section{One CS-only trial does not induce reconsolidation of the acquisition memory}

What consolidation process is induced by one CS-only trial? As shown above, presentation of one CS-only trial does not result in extinction 1-48 h later (Fig. 1). If any consolidation process is induced by one CS-only trial, it should be the reconsolidation of the acquisition memory, because this consolidation process leads to a stabilization of the acquisition memory. Only inhibition of the reconsolidated acquisition memory would result in a reduced conditioned response. To determine whether one CS-only trial induces reconsolidation of the acquisition memory, the same experiment was performed as described above. Only the number of CS-only trials presented on day 2 was changed from two CSonly trials, $30 \mathrm{~min}$ after the injection, to one CS-only trial. Nonretrieved control groups were not included in the experiment this time, because in both experiments described above (five CS-only trials; two CS-only trials), the emetine treatment alone, administered $24 \mathrm{~h}$ after acquisition, had no effect on memory retention $24 \mathrm{~h}$ after the emetine injection on day 2 . Both retrieved groups (PBS-retrieved and emetine-retrieved) showed a similar percentage of animals reacting at the CS-only trial by extending their proboscis (Fig. 7A). Thus, the emetine injection had no influence on the reduction in response probabilities after one CS-only trial. Differences between the PBS-retrieved and emetine-retrieved CRs on day 3 were not significant $\left(\mathrm{G}_{24 \mathrm{~h}}=0.64, \mathrm{NS} ; \mathrm{df}=1\right)$.

As a control for the activity of emetine, a parallel experiment was performed in which emetine and PBS, respectively, were injected $30 \mathrm{~min}$ before acquisition with three conditioning trials with an intertrial interval of $10 \mathrm{~min}$ on day 1 (Fig. $7 B$ ). On day 2, the $24 \mathrm{~h}$ memory of both groups was retrieved to prove the inhibiting effect of emetine on the induced consolidation effect. The emetine injection $30 \mathrm{~min}$ before three trial conditionings led to a significant decrease of the CR in the emetine-treated group
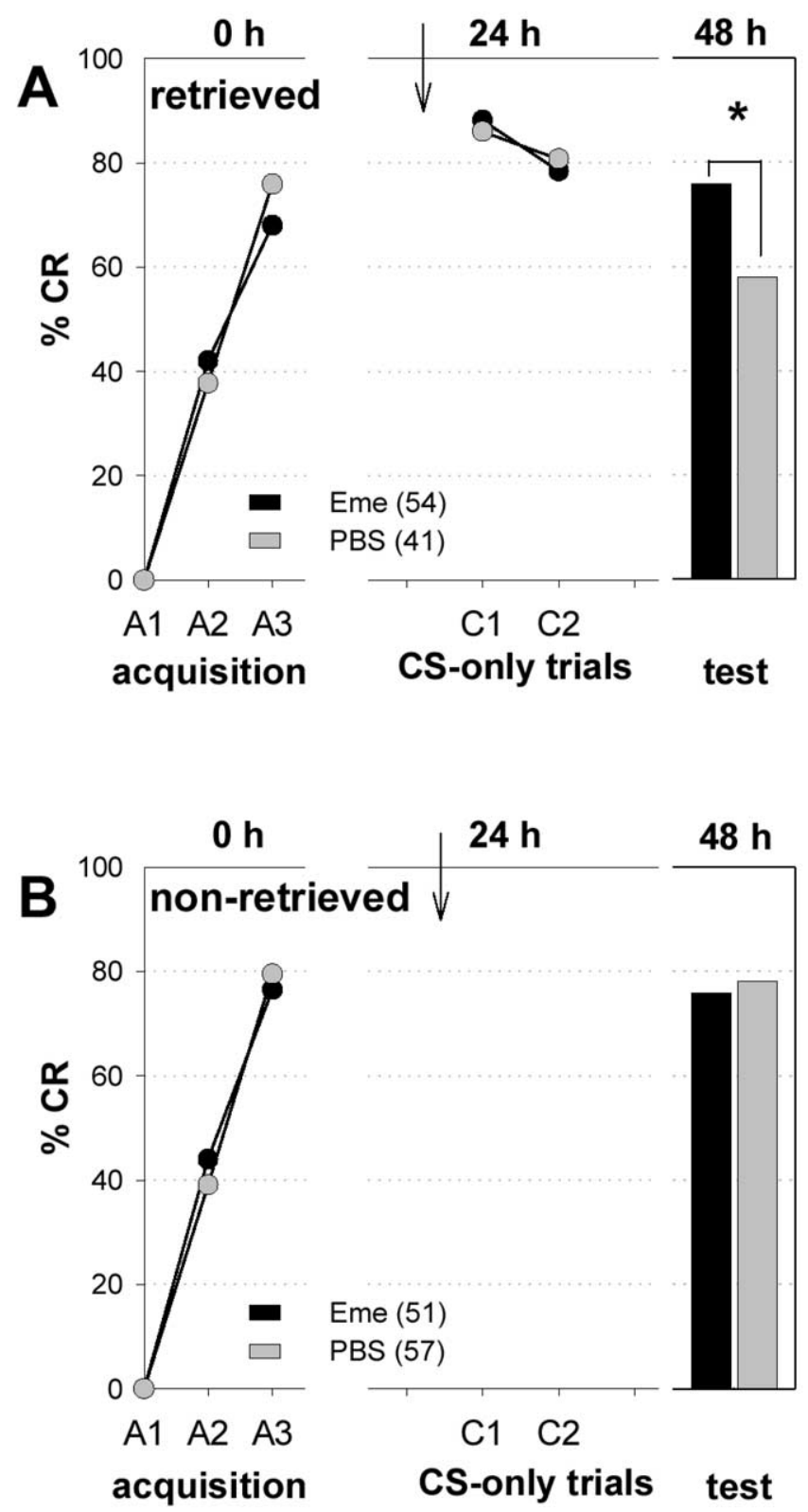

Figure 6. Emetine (Eme; $10 \mathrm{~mm}$ ) applied systemically $30 \mathrm{~min}$ before presentation of two CS-only trials blocks extinction at a $24 \mathrm{~h}$ retention test. $0 \mathrm{n}$ day 1 , animals were subjected to three CS-US pairings (A1-A3) with an ITI of 10 min (acquisition). After $24 \mathrm{~h}$, on day 2, emetine was injected into the flight muscle 30 min before two CS-only trials (C1, C2) with an ITI of $10 \mathrm{~min}$. On day 3, memory was tested (retention test). The asterisk indicates a significant difference between the CRs $(p<0.05)$. $\boldsymbol{A}$, Retrieved groups (emetine, $n=54 ; \mathrm{PBS}, n=41)$. $\boldsymbol{B}$, Nonretrieved groups (emetine, $n=51 ; \mathrm{PBS}, n=57$ ). Arrow, Time of injection; gray, PBS-injected control group; black, emetine-injected group; \% CR, percentage of animals that showed a proboscis extension response during $\mathrm{CS}$ presentation.

compared with the PBS-treated group $\left(\mathrm{G}_{24 \mathrm{~h}}=5.76 ; p=<0.05\right.$; $\mathrm{df}=1)$. Hence, emetine inhibited the consolidation of a $24 \mathrm{~h}$ acquisition memory and is therefore active. We conclude that one CS-only trial does not induce reconsolidation of the acquisition memory.

\section{Discussion}

Exposing an animal to a learned stimulus without reinforcement will retrieve the consolidated memory and initiate two consolidation processes: consolidation of an extinction memory and reconsolidation of the acquisition memory. This has been dem- 

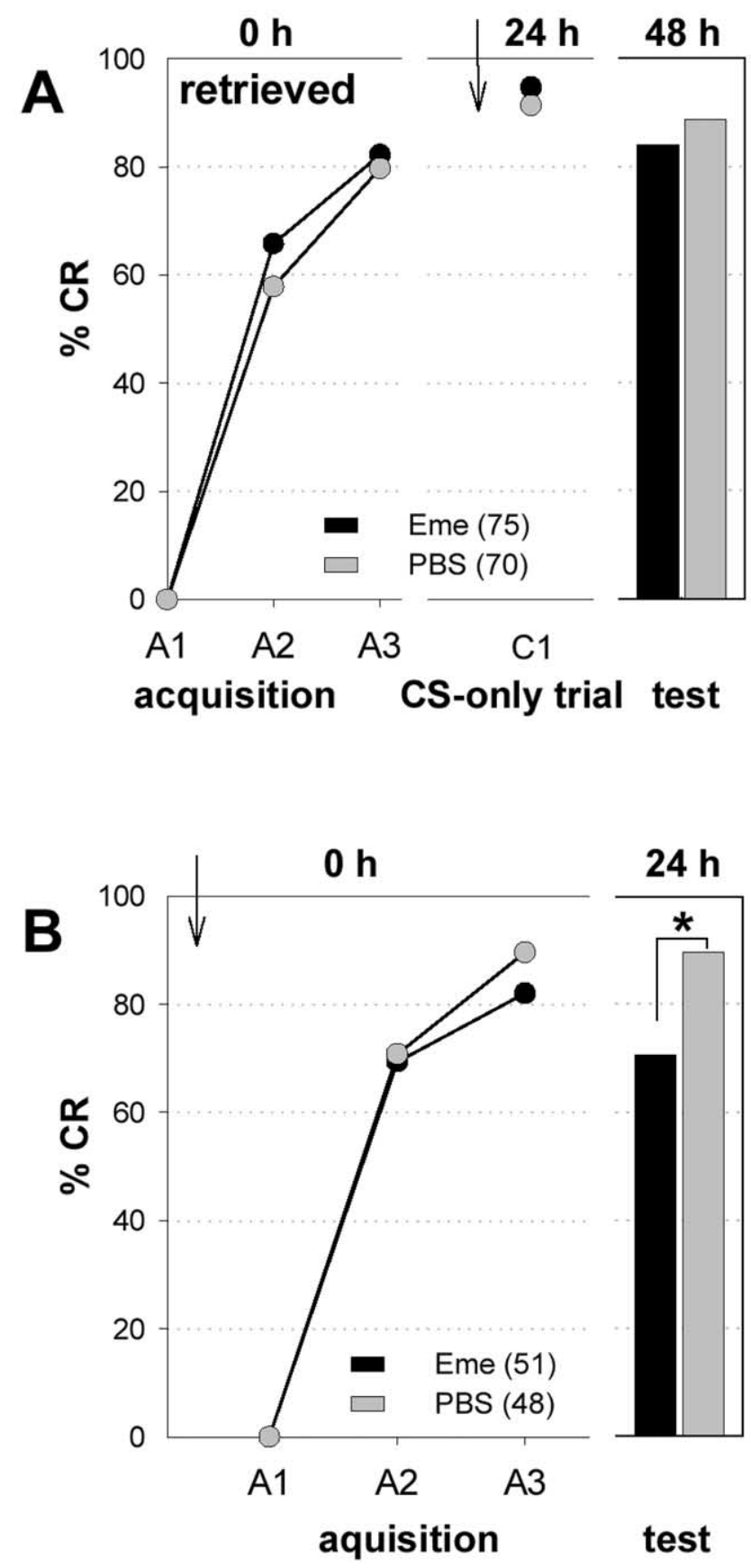

Figure 7. Emetine (Eme; $10 \mathrm{~mm}$ ) applied systemically $30 \mathrm{~min}$ before presentation of one CS-only trial does not block extinction or spontaneous recovery at a $24 \mathrm{~h}$ retention test. 0 day 1 , animals were subjected to three CS-US pairings (A1-A3) with an ITI of 10 min (acquisition). After $24 \mathrm{~h}$, on day 2, emetine was injected into the flight muscle 30 min before one (S-only trial (C1). On day 3, memory was tested (retention test). The asterisk indicates a significant difference between the CRs $(p<0.05)$. $\boldsymbol{A}$, Retrieved groups (emetine, $n=75$; PBS, $n=70)$. $\boldsymbol{B}$, Control experiment: emetine $(10 \mathrm{~mm})$ applied systemically $30 \mathrm{~min}$ before acquisition blocks long-term memory at $24 \mathrm{~h}$ after acquisition. Emetine was injected into the flight muscle $30 \mathrm{~min}$ before three CS-US pairings with an ITI of $10 \mathrm{~min}$ (acquisition). Memory was tested $24 \mathrm{~h}$ after acquisition (retention test) (emetine, $n=51 ; \mathrm{PBS}, n=48$ ). Arrow, Time of injection; gray, PBS-injected control group; black, emetine-injected group; \% CR, percentage of animals that showed a proboscis extension response during $C S$ presentation.

onstrated in several aversive learning paradigms in different animals (Dudai and Eisenberg, 2004). Nader (2003) and Dudai (2004) proposed in a hypothesis of trace dominance that there is a competition between consolidation of extinction memory and reconsolidation of acquisition memory with the dominant one being the one most affected by protein synthesis inhibition. In this study, we tested the hypothesis of trace dominance in an appetitive learning paradigm in an insect, the honeybee (Apis mellifera).

We aimed to further elucidate the role of the nonreinforced CS trial by studying the impact of one, two, and five CS-only trials on retention of a consolidated memory at different time intervals after the CS-only presentation. We found that both the extent and the kinetics of retention are severely affected by the number of CS-only trials. One CS-only trial has no effect on retention $24 \mathrm{~h}$ later, whereas two and five CS-only presentations reduce retention and hence result in extinction. Retention after five trials is lower than that after two trials, although spontaneous recovery compensates for part of the extinction effect.

We asked whether different numbers of CS-only trials induce the same or different consolidation processes. We found that one CS-only trial does not lead to memory consolidation. Two CSonly trials induce the consolidation of an extinction memory. Five CS-only trials induce a stronger extinction then two CS-only trials. However, an inhibition of extinction and, hence, the consolidation of this extinction memory are not visible. Instead, the opposing behavioral phenomenon of spontaneous recovery is blocked. Spontaneous recovery from extinction was first reported by Pavlov (1927) who stated that conditioned responses that had been extinguished spontaneously recovered over time. Pavlov (1927) concluded that "extinction must be regarded as a special form of inhibition. . . that it cannot be regarded as a. . . destruction of the conditioned reflex. .. " Today the behavioral phenomenon of spontaneous recovery is accepted as the reappearance of the acquisition memory: the acquisition memory persists, at least partially, after extinction, and it is only temporarily suppressed after extinction learning (Rescorla, 2004). This indicates that extinction represents a new learning process that does not destroy the old CS-US association. Therefore, an animal stores two opposing memories after extinction learning about the meaning of the CS: one regarding the CS-no US association, the extinction memory, and one regarding the CS-US association, the acquisition memory, which reflects spontaneous recovery (Bouton, 2004).

We found that the protein-synthesis inhibitor emetine inhibits spontaneous recovery after five CS-only trials. Hence, emetine inhibits the memory for the CS-US association, the acquisition memory. This means that five CS-only trials transfer the acquisition memory from an inactive memory trace into an active memory trace that is inhibited by emetine. This process is referred to as reconsolidation (Sara, 2000; Nader, 2003). Therefore, five CSonly trials result in reconsolidation of the acquisition memory that reflects spontaneous recovery.

In a recent study on extinction of contextual fear memory in mice, Fischer et al. (2004) demonstrated that the combination of CS-only trials and the application of a protein-synthesis inhibitor lead to a decrease in memory retention. This behavioral effect resembles our result on retrieval with five CS-only trials. Nevertheless, Fischer et al. (2004) interpreted their data substantially different than how we did. They argued that the applied inhibitor does not block reconsolidation of the acquisition memory, but that it targets the extinction by accelerating it. This would mean that CS-only trials activate protein synthesis-dependent processes counteracting extinction. If this is true, retrieval of an acquisition memory does not induce any new learning process about the old CS-US association and does not induce a reconsolidation process. Instead, retrieval of the acquisition memory 
results in extinction learning about the CS-no US association, leading to a protein synthesis-dependent inhibition of extinction memory. In our case, this explanation is insufficient. We demonstrate that consolidation of both acquisition memory and extinction memory after two CS-only trials are inhibited by emetine. Arguing for the study by Fischer et al. (2004) would then mean that the protein-synthesis inhibitor emetine blocks consolidation of acquisition memory and consolidation of extinction memory after two CS-only trials. However, the same drug in the same dose injected into the same region facilitates consolidation of extinction if injected before five CS-only trials, which is an inconsistent explanation. Alternatively, one would have to propose that the application of protein-synthesis inhibitors after acquisition might not target consolidation of the acquisition memory at all. Instead, it might accelerate forgetting. Accordingly, the application of protein-synthesis inhibitors at approximately the time of retrieval might not block consolidation of extinction memory but might strengthen the acquisition memory. This view would challenge the entire concept of protein synthesis-dependent memory and its underlying mechanism, the "cellular consolidation" (Dudai, 2004), that has been characterized intensively (Kandel, 2001). Together, an acceleration of extinction memory by emetine does not parsimoniously explain the inhibition of spontaneous recovery after five CS-only trials. Instead, our data indicate that spontaneous recovery reflects the reconsolidation of the acquisition memory. Accordingly, our study demonstrates for the first time that the acquisition memory reappearing after extinction and underlying spontaneous recovery does not undergo one protein synthesis-dependent consolidation process after the training and persist, unchanged from then on. Rather, it undergoes a consolidation process induced by the presentation of CSonly trials.

Our findings contradict what was expected from several studies on aversive learning paradigms (Eisenberg et al., 2003; Pedreira and Maldonado, 2003; Sangha et al., 2003a,b; Suzuki et al., 2004). These studies demonstrate that a weak CS-only trial or a single CS-only trial results in the reconsolidation of acquisition memory, whereas a strong CS-only trial or many CS-only trials induce consolidation of the extinction memory. In our study, no consolidation process after one CS-only trial is induced. A similar result was obtained by Suzuki et al. (2004) who demonstrated that a 1 min CS-only exposure does not result in any consolidation process. Hence, in their experiments as well as in ours, the strength of the CS-only trial is not sufficient to induce any consolidation process at all.

In our study, only two CS-only trials resulted in consolidation of extinction memory, whereas five CS-only trials resulted in reconsolidation of acquisition memory. This is the reverse of what has been demonstrated in previous studies on aversive learning (Eisenberg et al., 2003; Pedreira and Maldonado, 2003; Suzuki et al., 2004). One reason is the induction of spontaneous recovery by many CS-only trials in our study that compensates the effect of extinction and that has not been demonstrated in studies on aversive learning. Our study demonstrates that the induction of spontaneous recovery depends on the number of CS-only trials when retrieving a consolidated memory. A similar dependency of the kinetics of spontaneous recovery on the number of CS-only trials has been described by Berman et al. (2003). We therefore propose that the number or the strength of the extinction trials applied in the studies by Eisenberg et al. (2003), Pedreira and Maldonado (2003), and Suzuki et al. (2004) was not sufficient to induce spontaneous recovery, and hence no reconsolidation of the acquisition was visible after many CS-only trials.
These differences in the induction of spontaneous recovery might be a result of different properties of appetitive and aversive learning paradigms.

In untreated animals, extinction of CR as well as spontaneous recovery $24 \mathrm{~h}$ after five CS-only trials are incomplete. The $\mathrm{CR}$ is significantly increased compared with the last extinction trial, and it is significantly decreased compared with the nonretrieved group. Hence, extinction is only partially recovered. Therefore, we suppose that five CS-only trials induce two memory traces: a reconsolidated acquisition memory and an extinction memory. Nevertheless, we were not able to demonstrate blocking of the consolidation of the extinction memory. This is most likely because of the opposite behavioral effects resulting in blocking of both memories. If the behavioral effect of blocking the consolidation of extinction memory is smaller than the effect of blocking the reconsolidation of acquisition memory, the former is not visible in behavior. Hence, we cannot rule out the possibility that five CS-only trials induce two consolidation processes.

The hypothesis of trace dominance proposes a competition between consolidation of extinction memory and reconsolidation of acquisition memory "with the dominant one being the one most affected by protein synthesis inhibition" (Nader, 2003). Our data confirm this hypothesis by showing that after two CSonly trials on extinction memory, dominating behavior is inhibited during the time of its consolidation. Nevertheless, after five CS-only trials, we observed an incomplete spontaneous recovery and hence an incomplete extinction. In this case, the behavior is most likely not dominated by one memory trace. Two memory traces might determine the behavioral response after retrieval. Accordingly, we suggest that consolidation processes induced by memory retrieval take place in parallel rather than follow an "allor-nothing" law. The retrieval of these consolidated memories should then result in a retention that mirrors the balance of both consolidation processes, which most likely depends on the number of CS-only trials presented.

\section{References}

Anokhin KV, Tiunova AA, Rose SP (2002) Reminder effects-reconsolidation or retrieval deficit? Pharmacological dissection with protein synthesis inhibitors following reminder for a passive-avoidance task in young chicks. Eur J Neurosci 15:1759-1765.

Berman DE, Dudai Y (2001) Memory extinction, learning anew, and learning the new: dissociations in the molecular machinery of learning in cortex. Science 291:2417-2419.

Berman DE, Hazvi S, Stehberg J, Bahar A, Dudai Y (2003) Conflicting processes in the extinction of conditioned taste aversion: behavioral and molecular aspects of latency, apparent stagnation, and spontaneous recovery. Learn Mem 10:16-25.

Bitterman ME, Menzel R, Fietz A, Schäfer S (1983) Classical conditioning of proboscis extension in honeybees (Apis mellifera). J Comp Psychol 97:107-119.

Bouton ME (2004) Context and behavioral processes in extinction. Learn Mem 11:485-494.

Child FM, Epstein HT, Kuzirian AM, Alkon DL (2003) Memory reconsolidation in Hermissenda. Biol Bull 205:218-219.

Debiec J, LeDoux JE, Nader K (2002) Cellular and systems reconsolidation in the hippocampus. Neuron 36:527-538.

Dudai Y (2004) The neurobiology of consolidations, or, how stable is the engram? Annu Rev Psychol 55:51-86.

Dudai Y, Eisenberg M (2004) Rites of passage of the engram: reconsolidation and the lingering consolidation hypothesis. Neuron 44:93-100.

Eisenberg M, Kobilo T, Berman DE, Dudai Y (2003) Stability of retrieved memory: inverse correlation with trace dominance. Science 301:1102-1104.

Fischer A, Sananbenesi F, Schrick C, Spiess J, Radulovic J (2004) Distinct roles of hippocampal de novo protein synthesis and actin rearrangement in extinction of contextual fear. J Neurosci 24:1962-1966. 
Kandel ER (2001) The molecular biology of memory storage: a dialogue between genes and synapses. Science 294:1030-1038.

Kuwabara M (1957) Bildung des bedingten Reflexes von Pavlovs Typus bei der Honigbiene, Apis mellifica. J Fac Sci Hokkaido Univ Ser VI Zool $13: 458-464$.

Menzel R (2001) Searching for the memory trace in a mini-brain, the honeybee. Learn Mem 8:53-62.

Menzel R, Erber J, Masuhr T (1974) Learning and memory in the honeybee. In: Experimental analysis of insect behaviour (Barton-Browne L, ed), pp 195-217. Berlin: Springer.

Myers KM, Davis M (2002) Behavioral and neural analysis of extinction. Neuron 36:567-584.

Nader K (2003) Memory traces unbound. Trends Neurosci 26:65-72.

Nader K, Schafe GE, Le Doux JE (2000) Fear memories require protein synthesis in the amygdala for reconsolidation after retrieval. Nature 406:722-726.

Pavlov IP (1927) Conditioned reflexes: an investigation of the activity of the cerebral cortex, Lecture III, p 60. Oxford: Oxford UP.

Pedreira ME, Maldonado H (2003) Protein synthesis subserves reconsolidation or extinction depending on reminder duration. Neuron 38:863-869.

Pedreira ME, Perez-Cuesta LM, Maldonado H (2002) Reactivation and reconsolidation of long-term memory in the crab Chasmagnathus: protein synthesis requirement and mediation by NMDA-type glutamatergic receptors. J Neurosci 22:8305-8311.

Rescorla RA (2004) Spontaneous recovery. Learn Mem 11:501-509.

Sangha S, Scheibenstock A, Lukowiak K (2003a) Reconsolidation of a longterm memory in Lymnaea requires new protein and RNA synthesis and the soma of right pedal dorsal 1. J Neurosci 23:8034-8040.
Sangha S, Scheibenstock A, Morrow R, Lukowiak K (2003b) Extinction requires new RNA and protein synthesis and the soma of the cell right pedal dorsal 1 in Lymnaea stagnalis. J Neurosci 23:9842-9851.

Santini E, Ge H, Ren K, Pena DO, Quirk GJ (2004) Consolidation of fear extinction requires protein synthesis in the medial prefrontal cortex. J Neurosci 24:5704-5710.

Sara SJ (2000) Retrieval and reconsolidation: toward a neurobiology of remembering. Learn Mem 7:73-84.

Sekiguchi T, Yamada A, Suzuki H (1997) Reactivation-dependent changes in memory states in the terrestrial slug Limax flavus. Learn Mem $4: 356-364$

Spear N (1973) Retrieval of memory in animals. Psychol Rev 80:163-194.

Suzuki A, Josselyn SA, Frankland PW, Masushige S, Silva AJ, Kida S (2004) Memory reconsolidation and extinction have distinct temporal and biochemical signatures. J Neurosci 24:4787-4795.

Vianna MR, Szapiro G, McGaugh JL, Medina JH, Izquierdo I (2001) Retrieval of memory for fear-motivated training initiates extinction requiring protein synthesis in the rat hippocampus. Proc Natl Acad Sci USA 98:12251-12254.

Wüstenberg D, Gerber B, Menzel R (1998) Short communication: longbut not medium-term retention of olfactory memories in honeybees is impaired by actinomycin D and anisomycin. Eur J Neurosci 10:2742-2745.

Yamada A, Sekiguchi T, Suzuki H, Mizukami A (1992) Behavioral analysis of internal memory states using cooling-induced retrograde amnesia in Limax flavus. J Neurosci 12:729-735.

Zar JH (1997) Biostatistical analysis. Englewood Cliffs, NJ: Prentice Hall. 